\title{
CEDAW, derechos y mujeres en México
}

CEDAW, Rights and Women in Mexico

\author{
Eduardo Torres Alonso' (iD 0000-0002-0868-2240 \\ 'Universidad Nacional Autónoma de México, Facultad de Ciencias Políticas y Sociales, \\ Ciudad de México, México. 04510 - sociedadinstitucionesyrecursos@gmail.com
}

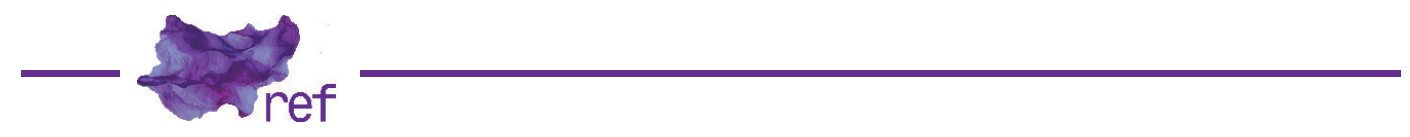

RAMÍREZ HERNÁNDEZ, Gloria.

Los derechos político-electorales de las mujeres en México ante la CEDAW.

México: Tribunal Electoral del Poder Judicial de la Federación, 2020.

La literatura sobre los derechos de las mujeres cada vez es más numerosa y diversa. Se reflexiona desde la ciencia política, la sociología y la historia, los estudios de género, la filosofía, las relaciones internacionales; por supuesto, también, desde el derecho. Mujeres, hombres y personas con identidades de género diversas, han acometido la tarea de estudiar y enseñar sobre dicha matera ya que al hacerlo ayudan a combatir una exclusión y discriminación hacia un grupo, en este caso las mujeres, exclusión y discriminación, también, que viven otros grupos sociales.

Los derechos político-electorales de las mujeres en México ante la CEDAW, libro de Gloria Ramírez Hernández (2020), profesora universitaria y activista por los derechos de las mujeres conjunta con rigor y tino reflexiones provenientes de las disciplinas antes mencionadas, convirtiéndolo propiamente en un estudio académico, pero tiene otra naturaleza: es un llamado a la actuación para no cejar en el esfuerzo de defensa de las mujeres.

Seis capítulos integran el libro, además de un apartado de conclusiones. Se agregan una sección de bibliografía especializada sobre la Convención sobre la Eliminación de Todas las Formas de Discriminación Contra la Mujer (CEDAW), un glosario CEDAW en materia de derechos político-electorales y un apartado de bibliografía sobre la defensa y promoción de los derechos político-electorales. Estos tres últimos apartados favorecen, principalmente, a los estudiantes de grado y posgrado que busca fuentes para realizar sus propias investigaciones. Se advierte la vena docente de la autora.

En el primero de ellos, "La CEDAW y los parámetros internacionales de los derechos político-electorales: marco teórico, metodológico y conceptual”, se ofrece una reflexión sobre la condición de las mujeres en el marco de la división vida pública versus vida privada y de la estructura patriarcal, partiendo de las reflexiones de autores como Aristóteles, Jean-Jacques Rousseau, Kant, Schopenhauer, Freud o Nietzsche y otros más que establecieron las bases de la dicotomía de la vida y de la división social/sexual del trabajo. Con estos antecedentes, pasa a examinar el reconocimiento de los derechos fundamentales a las mujeres y las luchas y movilizaciones que ellas llevaron a cabo para lograr ser consideradas ciudadanas. Uno de los acápites más interesantes de este capítulo es el destinado a describir y explicar la Convención sobre la Eliminación de Todas las Formas de Discriminación Contra la Mujer, siendo ésta uno 
de los nueve instrumentos de alcance internacional que integra la estructura jurisdiccional del sistema internacional de los derechos humanos para su promoción y protección.

En el capítulo siguiente, "Historia de los derechos político-electorales de las mujeres en México", pasa revista a algunos de los momentos más significativos en a lucha de las mexicanas en busca de la satisfacción de su demanda por el reconocimiento efectivo de sus derechos político-electorales. El trazo de la genealogía del movimiento de lucha femenino y feminista inicia con las conocidas e importantes obras de Olympe de Gouges, Declaración de los Derechos de la Mujer y de la Ciudadana, y de Mary Wollstonecraf, Vindicación de los derechos de la mujer. A partir de estos antecedentes, se reconstruye un recorrido del movimiento feminista en el mundo. En México, el asunto de los derechos de las mujeres, particularmente el derecho al voto, fue puesto sobre la mesa, entre 1884 y 1887 , por Laureana Wrigth, en su revista Violetas del Anáhuac. Luego, la autora enumera y describe las acciones de las mujeres que participaron en la lucha por la Independencia nacional y en la Revolución mexicana. Mención especial merece Hermila Galindo quien fue una sufragista importantísima y que solicitó el voto femenino en el Congreso Constituyente de 1916-1917. Finalmente, a las mujeres se les reconoce votar, primero, en 1947 para elecciones municipales y, después, para elecciones federales en 1953. En ocasión del 60 aniversario del voto femenino, el presidente de México envió, en octubre de 2013, una iniciativa de reforma constitucional para establecer la paridad en las candidaturas a cargos de elección popular.

Por su parte, en el capítulo tercero, "Enfoque basado en derechos humanos y juzgar con perspectiva de género", se presenta un estudio pormenorizado de esta perspectiva basada en los derechos humanos, que permite identificar quiénes son las personas titulares de derecho, con qué mecanismos cuentan los titulares de derechos para hacerlos valer, quiénes están obligados a proteger o garantizar los derechos en cada territorio, según particularidades y sus obligaciones, cuáles son los mecanismos que existen para conocer lo que están haciendo los titulares de obligaciones para garantizar cada uno de los derechos o el derecho en evaluación, cuáles son las instituciones que están involucradas en las acciones que deben desarrollarse para garantizar los derechos, y cuál es la capacidad de las instituciones y los programas o proyectos para la garantía de esos derechos. De igual manera, se reflexiona sobre la transversalidad de género y los estándares internacionales en materia de justicia desde la perspectiva de género; sobresale el análisis de casos paradigmáticos de paridad de género y la CEDAW: Jurisprudencia 20/2018. Paridad de género. Los partidos políticos tienen la obligación de garantizarla en la integración de sus órganos de dirección; Sentencia SUP-REC-1279/2017. Asignación de regidurías de representación proporcional; SUP-REC-1334/2017. Integración de legislaturas locales; Tesis $\mathrm{XXIV/2018.} \mathrm{Acciones} \mathrm{afirmativas} \mathrm{indígenas.} \mathrm{A} \mathrm{través} \mathrm{de} \mathrm{un} \mathrm{trato} \mathrm{diferenciado} \mathrm{justificado} \mathrm{aseguran}$ que la población indígena acceda a cargos de elección popular, entre otras.

Las recomendaciones generales en materia de violencia contra las mujeres emitidas por el Comité CEDAW, como los estándares internacionales respecto a la violencia política contra las mujeres en el sistema universal y en el sistema interamericano de derechos humanos, es lo que se estudia en el cuarto capítulo titulado "Recomendaciones generales de la CEDAW vinculadas a la justicia electoral". La Recomendación general No. 12 acerca de la violencia contra las mujeres representó el inicio de un proceso gradual que en 1991 se amplió y en 1992 dio pie a su actualización con la Recomendación general No. 19 sobre la violencia contra las mujeres, la cual fue más específica en sus orientaciones, con base en el análisis que el Comité CEDAW realizó de los informes de los Estados parte, con el objetivo de mejorar la aplicación de la CEDAW en esta materia. Con la Recomendación general No. 19, el Comité precisó que los informes de los Estados parte no siempre reflejaban de manera apropiada la estrecha relación entre la discriminación y la violencia contra las mujeres, las violaciones de los derechos humanos y las libertades fundamentales. Por su parte, con la Recomendación general No. 35 acerca de la violencia en razón de género contra las mujeres, por la que se actualiza la Recomendación general No. 19, el Comité CEDAW avanza en al reconocer a la violencia en razón de género como un concepto, una categoría analítica y un elemento fundamental que representa un gran obstáculo para la igualdad de las mujeres en todos los ámbitos.

"Metodología de seguimiento de las recomendaciones de la CEDAW en materia de derechos político-electorales en México" es el quinto capítulo y está destinado a exponer la manera en que evalúan las recomendaciones del Comité CEDAW al Estado mexicano. Para ello, se presentan indicadores cualitativos y cuantitativos, mismos que deben integrarse en estructurales, de proceso y de resultado. Para mostrar el estado de cumplimiento, se emplea el semáforo de cumplimiento, el cual fue desarrollado en el marco de los estudios de la Cátedra UNESCO de Derechos Humanos de la Universidad Nacional Autónoma de México, que es coordinada por la autora del libro que se comenta. Ahora bien, con relación a las 201 recomendaciones que el Comité CEDAW ha hecho al Estado mexicano, siete son en materia de participación en la vida política y pública. 
Finalmente, el capítulo que cierra la obra es "Sentencias en materia de justicia electoral vinculadas a la CEDAW", en donde la autora revisa el sistema judicial electoral y los derechos políticos de las mujeres y la manera en que éste ha dado respuesta a las recomendaciones del Comité CEDAW. La relación entre la CEDAW y el Tribunal Electoral del Poder Judicial de la Federación, máxima autoridad jurisdiccional en materia electoral, se encuentra en las sentencias que elabora éste y que refieren a la Convención. Si se revisan las sentencias, se advierte que las recomendaciones generales del Comité CEDAW mayormente referidas son, en primer lugar, la No. 23, acerca de la vida política y pública, con 63 expedientes; seguida de la No. 25, respecto a las medidas especiales de carácter temporal, con 41 expedientes, y, finalmente, la No. 19, que se refiere a la violencia contra las mujeres, con 31 expedientes. Entre los hallazgos al indagar en la labor jurisdiccional se puede mencionar que existen 716 expedientes que mencionan la Convención en el periodo de 2004 a 2018 (0.09\% del total de las sentencias); de esta muestra hubo 1,211 actores, de los cuales $46 \%$ son mujeres. Estos porcentajes reflejan el incremento del uso que hacen las mujeres de los tribunales para acceder a la justicia en comparación con otros actores, lo cual también significa que continúan los obstáculos para que accedan a los puestos de elección popular.

Este libro viene a incorporarse a las obras recientes que se están produciendo por académicas y académicos de la Facultad de Ciencias Políticas y Sociales de la Universidad Nacional Autónoma de México y que se están editado tanto por la misma universidad como por instituciones aliadas, como es el caso del libro que motiva esta reseña, entre ellas: Perspectivas sobre las mujeres en México: historia, administración pública y participación política (2018) y Mujeres y administración pública en los órdenes de gobierno en México. Capacidad de decisión y poder en el espacio público (2020), ambos coordinados por Fernando Pérez Correa y Gloria Luz Alejandre Ramírez, y Reflexiones interdisciplinarias sobre la ciudadanía de género. Mujeres en la Ciudad de México, coordinado por Lorena Umaña (2018).

\section{Referencias}

PÉREZ CORREA, Fernando; ALEJANDRE RAMÍREZ, Gloria Luz (coords.). Perspectivas sobre las mujeres en México: historia, administración pública y participación política. México: Facultad de Ciencias Políticas y Sociales, UNAM-La Biblioteca, 2018.

PÉREZ CORREA, Fernando; ALEJANDRE RAMÍREZ, Gloria Luz (coords.). Mujeres y administración pública en los órdenes de gobierno en México. Capacidad de decisión y poder en el espacio público. México: Facultad de Ciencias Políticas y Sociales, UNAM-La Biblioteca, 2020.

RAMÍREZ HERNÁNDEZ, Gloria. Los derechos político-electorales de las mujeres en México ante la CEDAW. México: Tribunal Electoral del Poder Judicial de la Federación, 2020.

UMAÑA, Lorena (coord.). Reflexiones interdisciplinarias sobre la ciudadanía de género. Mujeres en la Ciudad de México. México: Facultad de Ciencias Políticas y Sociales, UNAM-Orfila, 2020.

Eduardo Torres Alonso (etorres.alonso@politicas.unam.mx) estudió las licenciaturas en Ciencias Políticas y Administración Pública, en Desarrollo Municipal y Gobernabilidad, y en Derecho. Así como una maestría en Administración Pública. Es profesor de la Facultad de Ciencias Políticas y Sociales de la Universidad Nacional Autónoma de México y secretario técnico del Seminario Universitario de Estudios sobre Sociedad, Instituciones y Recursos de la UNAM.

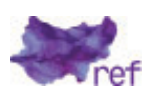


COMO CITAR ESTE ARTIGO DE ACORDO COM AS NORMAS DA REVISTA

TORRES ALONSO, Eduardo. "CEDAW, derechos y mujeres en México". Revista Estudos Feministas, Florianópolis, v. 29, n. 3, e76982, 2021

\section{CONTRIBUIÇĀO DE AUTORIA}

Não se aplica.

\section{FINANCIAMENTO}

Não se aplica.

\section{CONSENTIMENTO DE USO DE IMAGEM}

Não se aplica.

\section{APROVAÇĀO DE COMITÊ DE ÉTICA EM PESQUISA}

Não se aplica.

\section{CONFLITO DE INTERESSES}

Não se aplica.

\section{LICENÇA DE USO}

Este artigo está licenciado sob a Licença Creative Commons CC-BY 4.0 International. Com essa licença você pode compartilhar, adaptar, criar para qualquer fim, desde que atribua a autoria da obra.

\section{HISTÓRICO}

Recebida em 06/09/2020

Aceita em 12/10/2020 